\title{
FRACTURA HIDRÁULICA EN MÉXICO: UNA MIRADA DESDE LA REFORMA CONSTITUCIONAL ENERGÉTICA Y LOS DERECHOS COMUNITARIOS DE AGUA
}

\author{
FRACKING IN MEXICO: A REVIEW FROM \\ CONSTITUTIONAL ENERGY REFORM AND \\ COMMUNITARIAN WATER RIGHTS
}

\author{
Daniel JACOBO-MARÍN*
}

Recibido: 01/09/2019

Aceptado: $12 / 05 / 2020$

SUMARIO: I. Introducción. II. Reforma constitucional y nuevo marco legal energético en México, 2013-2014. III. Documentación prospectiva de hidrocarburos: el preámbulo de las licitaciones. IV. Regulación de la fractura hidráulica en México y perspectiva comparada con el marco europeo. V. Panorama mexicano sobre la fractura hidráulica frente al principio precautorio. VI. Los derechos comunitarios de agua en el contexto del nuevo marco legal energético. VII. Consideraciones finales. VIII. Bibliografía. IX. Legislación. X. Siglas utilizadas. XI. Tablas (Anexos).

SumMARY: I. Introduction. II. Constitutional reform and new energy legislation in Mexico, 2013-2014. III. Prospective analysis of hydrocarbons: preamble of tenders. IV. Regulation of fracking in Mexico and perspective compared to the European framework. V. Mexican panorama about fracking and precautionary principle. VI. Communitarian water rights under new energy legislation. VII. Conclusions. VIII. Bibliography. IX. Legislation. X. Acronyms used. XI. Tables (Annexes).

Resumen: El artículo estudia la regulación sobre la obtención de hidrocarburos no convencionales mediante fractura hidráulica (fracking) en México. Para tal fin, se analiza la reforma constitucional energética aprobada en 2013 y el marco legal derivado de ésta. Se explica que, en términos de la narrativa empleada para obtener energéticos, se han puesto en riesgo los derechos comunitarios de agua. Se concluye que bajo el discurso de alcanzar la seguridad energética la reforma constitucional apuntaló el paradigma hegemónico de producción y consumo de energía fósil.

Palabras clave: Fractura hidráulica, derechos de agua, hidrocarburos no convencionales, seguridad energética, reforma energética.

Abstract: This paper studies the regulation on obtaining unconventional hydrocarbons through fracking in Mexico. To this aim, the energy constitutional reform approved in 2013 and the legal framework derived from it are analyzed. It is explained that, in terms of the narrative used to obtain energy resources, communal water rights have been put at risk. It is

\footnotetext{
* Profesor de Derecho de Aguas. Abogado ambientalista e integrante de la Clínica de Litigio Estratégico en Derechos Humanos de la UASLP. Correo electrónico: jacobo.marind@gmail.com ORCID: https://orcid.org/0000-0001-8379-1220
} 
concluded that under the discourse of achieving energy security the constitutional reform underpinned the hegemonic paradigm of fossil energy production and consumption.

Keywords: Fracking, Water Rights, Non-conventional hydrocarbons, Energy security, Energy reform.

\section{INTRODUCCIÓN}

El objetivo de este artículo es analizar la extracción de hidrocarburos mediante fractura hidráulica (fracking) en México. Con esa finalidad, se discute el marco normativo que avala la exploración y la extracción en yacimientos no convencionales. Se examina la reforma constitucional energética aprobada en diciembre de 2013 para documentar la apertura del sector de hidrocarburos a la inversión de empresas trasnacionales de capital privado. La reglamentación de la fractura hidráulica se problematiza con los aprovechamientos hidráulicos de pueblos indígenas y núcleos agrarios, que se expresan, en términos de este trabajo, como derechos comunitarios de agua. El artículo se orienta hacia la siguiente hipótesis: la legislación que derivó de la reforma energética aprovechó la coyuntura generada en la legislación sobre aguas nacionales para reglamentar la fractura hidráulica y, de ese modo, intervenir el orden de prelación de los usos del agua en México.

De acuerdo con la exposición de motivos del decreto de reforma, la implementación del nuevo modelo de producción e inversión reduciría la exposición del país a riesgos técnicos, operativos, financieros y ambientales y, adicionalmente, se promovería la generación de energías renovables. No obstante, la reglamentación derivada acondicionó el marco normativo e institucional para favorecer la extracción de insumos para la generación de energía fósil, de modo que los bienes naturales ubicados en el subsuelo mexicano se han canalizado hacia el mercado energético internacional. En aras de amplificar las actividades de exploración y extracción de hidrocarburos, se ha facilitado la aprobación de permisos para su refinación, transporte, almacenamiento, distribución y comercialización. Esta situación fue posible a través del otorgamiento de asignaciones a entidades estatales y contratos con empresas de capital privado.

El contenido central del artículo se estructura en seis partes. En el apartado II se aborda la reforma constitucional energética de 2013 y el marco legal derivado, para tal fin se emplea el contexto de la integración económica de América del Norte y, de forma particular, el ámbito del sector energético. Para ilustrar y describir tal proceso, se incorporan dos tablas anexas que contienen las iniciativas legislativas, su evaluación, materia, naturaleza normativa y ordenamientos derivados, así como la concordancia respectiva. El apartado III documenta la selección prospectiva de yacimientos potenciales de hidrocarburos, que tuvo como finalidad listarlos para eventualmente licitar las actividades que podrían realizarse en las rondas públicas internacionales. En el apartado IV se explica la reglamentación de la fractura hidráulica en México y se detalla de forma breve el marco regulatorio europeo sobre esta técnica. El apartado V se refiere al panorama mexicano sobre el fracking, considerando sus implicaciones y posibles efectos socioambientales en términos del principio precautorio. En el apartado VI se reflexiona sobre los 
derechos comunitarios de agua en el marco del nuevo orden legal energético; se describe el criterio patrimonial sobre las aguas nacionales y el orden de prelación sobre los usos, que no considera la demanda del líquido con fines de exploración y extracción de hidrocarburos no convencionales. El apartado VII corresponde a las consideraciones finales.

\section{REFORMA CONSTITUCIONAL Y NUEVO MARCO LEGAL ENERGÉTICO EN MÉXICO, 2013-2014}

El boom petrolero de la década de 1970 permitió que algunas naciones de América Latina, incluido México, recaudaran un importante caudal de recursos económicos que se emplearon en favor de una política desarrollista y de sustitución de importaciones. Posteriormente, el modelo energético se orientó hacia las fuentes renovables, impulsado por el progresivo agotamiento de las reservas de petróleo, la inequidad en la distribución de la renta petrolera, la importación de derivados pétreos refinados de alto costo, los problemas del sector eléctrico y los efectos ambientales nocivos generados por la producción energética. ${ }^{1}$

De acuerdo con la perspectiva oficial, la reforma constitucional en materia de energía (conocida genéricamente como reforma energética) gestó cambios institucionales, legales y de mercado que pretenden "reducir de forma paulatina la exposición del país a los riegos técnicos, operativos, financieros y ambientales relacionados con las actividades de exploración y extracción de petróleo y gas natural”. ${ }^{2}$ El diagnóstico gubernamental enfatizó la apertura del sector a la participación del capital trasnacional, de manera que la narrativa de los informes abundó sobre la insuficiente producción de energéticos y el incremento de importaciones de gas natural, gasolinas, diésel y petroquímicos. ${ }^{3}$

La reforma fue impulsada durante el gobierno de Enrique Peña Nieto, quien presentó la iniciativa el 12 de agosto de 2013 y, en el marco del Pacto por México, ${ }^{4}$ encontró respaldo en la mayoría de los integrantes del Senado y de la Cámara de Diputados. El decreto se publicó en el Diario Oficial de la Federación (DOF) el 20 de diciembre de 2013 que modificó los artículos 25, 27 y 28 constitucionales y estableció 21 artículos transitorios que mandataron al Congreso de la Unión la adecuación del marco normativo

\footnotetext{
${ }^{1}$ ISCH, E. (2015), “Geopolítica regional de la hidroenergía: ¿A dónde irá la energía de Ecuador y del resto de los países?”, (In) Justicia Hídrica. Resistencias y Alternativas en América Latina, no 2, CBC-Alianza Internacional Justicia Hídrica, Medellín, pp. 7-11.

${ }^{2}$ SECRETARÍA DE ENERGÍA (2017), Plan quinquenal de licitaciones para la exploración y extracción de hidrocarburos 2015-2019, Secretaría de Energía-Subsecretaría de Hidrocarburos, México, p. 9.

${ }^{3}$ ANGLÉS HERNÁNDEZ, M. (2017), "La reforma en materia de hidrocarburos en México, como parte del proyecto neoliberal hegemónico violatorio de derechos humanos”, Reforma en materia de hidrocarburos. Análisis jurídicos, sociales y ambientales en prospectiva, IIJ-UNAM-Universidad Autónoma de Tamaulipas, México, p. 134.

${ }^{4}$ El Pacto por México fue firmado el 2 de diciembre de 2012 en Ciudad de México por Enrique Peña Nieto y los representantes del Partido Revolucionario Institucional, el Partido Acción Nacional y el Partido de la Revolución Democrática, el Partido Verde Ecologista de México lo signó el 28 de enero de 2013. Se trató de un acuerdo de las cúpulas políticas partidistas que dio paso a las reformas constitucionales y reglamentarias en materia de telecomunicaciones, educativa, hacendaria, fiscal y energética.
} 
necesario. ${ }^{5} \mathrm{La}$ reglamentación derivada incluyó la expedición de nueve leyes y la modificación de otras 12 mediante seis decretos divulgados en el DOF el 11 de agosto de 2014.

La propuesta de modificación legislativa incluyó nueve iniciativas enviadas por el Poder Ejecutivo al Senado de la República en materia de hidrocarburos, energía eléctrica, geotermia, seguridad industrial y ambiental, empresas productivas del Estado, fiscalización, fondo petrolero e ingresos al presupuesto nacional; tres de las iniciativas se turnaron a la Cámara de Diputados por tratarse de leyes en materia fiscal, presupuestaria y de ingresos al Estado (véase la tabla 1). El nuevo orden jurídico incluyó la expedición de la legislación reglamentaria que renovó el marco energético en México (véase la tabla 2).

La modificación constitucional puso fin al modelo político-económico que existía desde la nacionalización de la industria petrolera propuesta por el presidente Lázaro Cárdenas en 1938 y concretada el 20 de enero de 1960, ${ }^{6}$ que otorgó al sector de hidrocarburos la categoría de área estratégica y prioritaria. ${ }^{7}$ Para contextualizar tal hecho histórico, debe recordarse que la nacionalización detonó el golpeteo político de los empresarios extranjeros, incluido el boicot de la compañía Standard Oil Company (propiedad de la corporación Royal Dutch-Schell) que obstaculizó la comercialización de crudo mexicano en Europa y otras regiones. Las presiones de los consorcios norteamericanos expropiados no se limitaron a promover medidas comerciales coactivas, también dificultaron la anuencia de la reforma al párrafo sexto del artículo 27 constitucional. La nacionalización de la industria petrolera en México incluyó una serie de medidas político-jurídicas que derivaron en otorgar a la empresa paraestatal Petróleos Mexicanos (Pemex) la exclusividad en la realización de las actividades. ${ }^{8}$

La transformación del modelo estatal mexicano de aprovechamiento de los hidrocarburos respondió, veinte años después, al proyecto de integración económica que se discutió infructuosamente en el capítulo energético del Tratado de Libre Comercio de América del Norte (TLCAN), suscrito en 1994 por los gobiernos de Canadá, Estados Unidos de América (EUA) y México. En este contexto, el reposicionamiento hegemónico de EUA en el mercado energético global desplegó una estrategia geopolítica para apuntalar la acumulación de yacimientos no convencionales. Para ello, la integración económica de

\footnotetext{
${ }^{5}$ DIARIO OFICIAL DE LA FEDERACIÓN (2013), Decreto por el que se reforman y adicionan diversas disposiciones de la Constitución Política de los Estados Unidos Mexicanos, en Materia de Energía, México, 20 de diciembre.

${ }^{6}$ Con el pretexto de consolidar la reforma constitucional de 20 de enero de 1960, el gobierno mexicano implementó en 1965 dos medidas emergentes: la suspensión de la importación de petrolíferos y el incremento de las reservas internas. Esta situación se justificó con el déficit productivo, la caída en la exportación del crudo y la necesidad de garantizar el abasto del mercado interno. El Estado mexicano buscó reformular la estrategia productiva e insertarse definitivamente en la industria energética global, argumentando el débil crecimiento económico originado por la escasa inversión privada.

${ }^{7}$ Un análisis detallado sobre la nacionalización de la industria petrolera en México puede consultarse en: BASSOLS BATALLA, N. (2006), Las etapas de la nacionalización petrolera, Porrúa, México.

${ }^{8}$ JACOBO-MARÍN, D. (2019), “Apología de la extracción, acumulación de derechos de agua y despojo por contaminación. Legados de la reforma energética en México”, Revista de Derechos Humanos y Estudios Sociales, año XI, nº 22, pp. 127-144.
}

Revista de Estudios Jurídicos n 20/2020 (Segunda Época)

ISSN-e 2340-5066. Universidad de Jaén (España)

Versión electrónica: rej.ujaen.es 
América del Norte fue el argumento que mantuvo a los hidrocarburos mexicanos como el objetivo pendiente de la agenda estadounidense. ${ }^{9}$

El capítulo energético del TLCAN, acordado en 1992, mantenía reservas por parte de México. No obstante, la posibilidad de alcanzar un acuerdo mantuvo la confianza en que las disposiciones sobre los hidrocarburos mexicanos se debilitarían con la inevitable integración energética de la región. En diciembre de 2012 la Comisión de Relaciones Exteriores del Senado estadounidense reconoció el interés sobre el petróleo y el gas de México; la declaración se hizo pública durante la discusión de la reforma constitucional publicada en 2013. ${ }^{10}$

Aunque se mantiene la narrativa constitucional sobre el sector energético como área estratégica y prioritaria, significa poco frente a los parámetros de economía neoliberal previstos en los acuerdos comerciales suscritos por México, debido a que promueven el modelo de mercado que limita la intervención del Estado y privilegia la inversión del capital trasnacional. ${ }^{11}$ En tal sentido, la reforma (oficialmente llamada estructural) respondió a dos procesos convergentes de política económica: la integración energética de América del Norte y el reposicionamiento hegemónico de EUA en el mercado energético internacional, cuyo modelo de mercado ha colocado los recursos fósiles como la principal fuente para la generación de energía.

De acuerdo con la iniciativa legislativa, se pretendió reforzar la rectoría del Estado en el sector, impulsar la generación de energías renovables y garantizar el abasto del mercado interno. Sin embargo, se trató de un discurso mediático que ocultó el fortalecimiento del paradigma de extracción, así lo muestran los documentos oficiales que subrayaron la insuficiente producción y la importación creciente de combustibles fósiles. Basta con leer el optimismo de los informes elaborados para el gobierno de EUA que elogiaron la apertura del sector energético mexicano. ${ }^{12}$

\section{DOCUMENTACIÓN PROSPECTIVA DE HIDROCARBUROS: EL PREÁMBULO DE LAS LICITACIONES}

La reforma constitucional implicó la elaboración de un marco normativo que promueve e incentiva la obtención de bienes naturales del subsuelo como insumos energéticos. Por esta razón, fue necesario definir técnicamente un conjunto de yacimientos prospectivos de hidrocarburos convencionales y no convencionales, en este proceso previo se identificaron y evaluaron depósitos potenciales. Dicha tarea fue encargada a la Secretaría de Energía (SENER) que, a través de la Comisión Nacional de Hidrocarburos (CNH), formuló el Plan quinquenal de licitaciones para la exploración y extracción de hidrocarburos 2015-2019, cuyos estudios situaron a la vertiente del Golfo de México como

\footnotetext{
${ }^{9}$ VARGAS, R. y BARRIOS, H. (2013), "El impacto geopolítico de la revolución del gas de esquisto: consideraciones para México”, El Cotidiano, nº 177, p. 62.

${ }^{10}$ VARGAS, R. (2015), “La reforma energética: a 20 años del TLCAN”, Problemas del Desarrollo, vol. 46, $\mathrm{n}^{\circ}$ 180, p. 105.

${ }^{11}$ CÁRDENAS GRACIA, J. (2014), Crítica a la reforma constitucional energética de 2013, IIJ-UNAM, México, pp. 61-62.

${ }^{12}$ WOOD, A. (2016), A Look at the Future of the Mexican Petroleum Industry after Energy Reform, Wilson Center-Mexico Institute, Washington.
}

Revista de Estudios Jurídicos nº 20/2020 (Segunda Época)

ISSN-e 2340-5066. Universidad de Jaén (España)

Versión electrónica: rej.ujaen.es 
la zona de mayor importancia (véase la figura 1). Con base en esta planificación, la ronda uno comprendió una serie de licitaciones públicas internacionales llevadas a cabo por el Estado mexicano para negociar contratos. De acuerdo con el Plan quinquenal, la ronda uno "dio inicio a la participación competitiva, tanto de empresas privadas como de empresas productivas del Estado en la extracción de petróleo y gas natural”. ${ }^{13}$

En la ronda cero la Secretaría de Energía adjudicó a Petróleos Mexicanos (Pemex) 489 asignaciones: 108 de exploración, 286 de extracción y 95 campos de producción asignados hasta su licitación. En términos de reservas probadas y probables se asignó a la empresa productiva del Estado un volumen de 20,589 millones de barriles de petróleo crudo equivalente. Las asignaciones facultan a Pemex para realizar extracción en los estados de Nuevo León, Tamaulipas, Veracruz, Hidalgo y San Luis Potosí; exploración no convencional en Coahuila, Nuevo León, Tamaulipas, San Luis Potosí, Hidalgo, Veracruz y Puebla; y exploración convencional en Tamaulipas, Nuevo León, San Luis Potosí, Veracruz, Tabasco y en aguas someras y profundas del Golfo de México. De acuerdo con los informes públicos, Pemex deberá mantener una producción de 2.5 millones de barriles diarios durante 15.5 años. ${ }^{14}$

Durante la ronda dos la empresa anglo-holandesa Shell dominó la mayor licitación petrolera, seguida por Petronas (Malasia), Chevron (EUA) e Inpex (Japón). Los resultados de la subasta evidencian que el subsuelo del Golfo de México se mantiene como un espacio promisorio. La empresa noruega Statoil anunció en 2015 un hallazgo petrolero a 350 kilómetros de la costa de Luisiana, el informe permitió inferir que la cantidad de reservas encontradas es generosa y, por lo tanto, la conquista de la frontera oceánica ultra profunda aún no concluye. ${ }^{15}$

La subasta energética demostró que el régimen jurídico protege la inversión privada y, simultáneamente, la política económica del ramo está orientada hacia el aprovechamiento masivo de los hidrocarburos (incluidos los no convencionales) con el objetivo de aumentar la generación de energía fósil. Sin embargo, la estrategia de licitación planificó actividades extractivas en tierras de propiedad social colectiva (territorios indígenas, núcleos ejidales y comunidades agrarias) cuyo patrimonio biocultural (tierras, aguas, montañas, bosques, pastos) será afectada con la ejecución de los proyectos. En este sentido, un análisis jurídico detallado permite observar la escasa previsión de mecanismos jurisdiccionales (administrativos y de protección de los derechos humanos) para salvaguardar los derechos territoriales de las comunidades potencialmente afectadas. ${ }^{16}$

\footnotetext{
13 SECRETARÍA DE ENERGÍA (2017), p. 13.

14 SECRETARÍA DE ENERGÍA (2017), p. 12.

${ }^{15}$ VERA VÁZQUEZ, R. (2015), “Actividad petrolera en el Golfo de México: historia, derrames y política internacional de integridad de los océanos”, Los hidrocarburos en el noreste de México, Universidad Autónoma de Tamaulipas-El Colegio de Tamaulipas, Ciudad Victoria, p. 15.

16 JACOBO-MARÍN, (2019), pp. 134 y ss.
} 


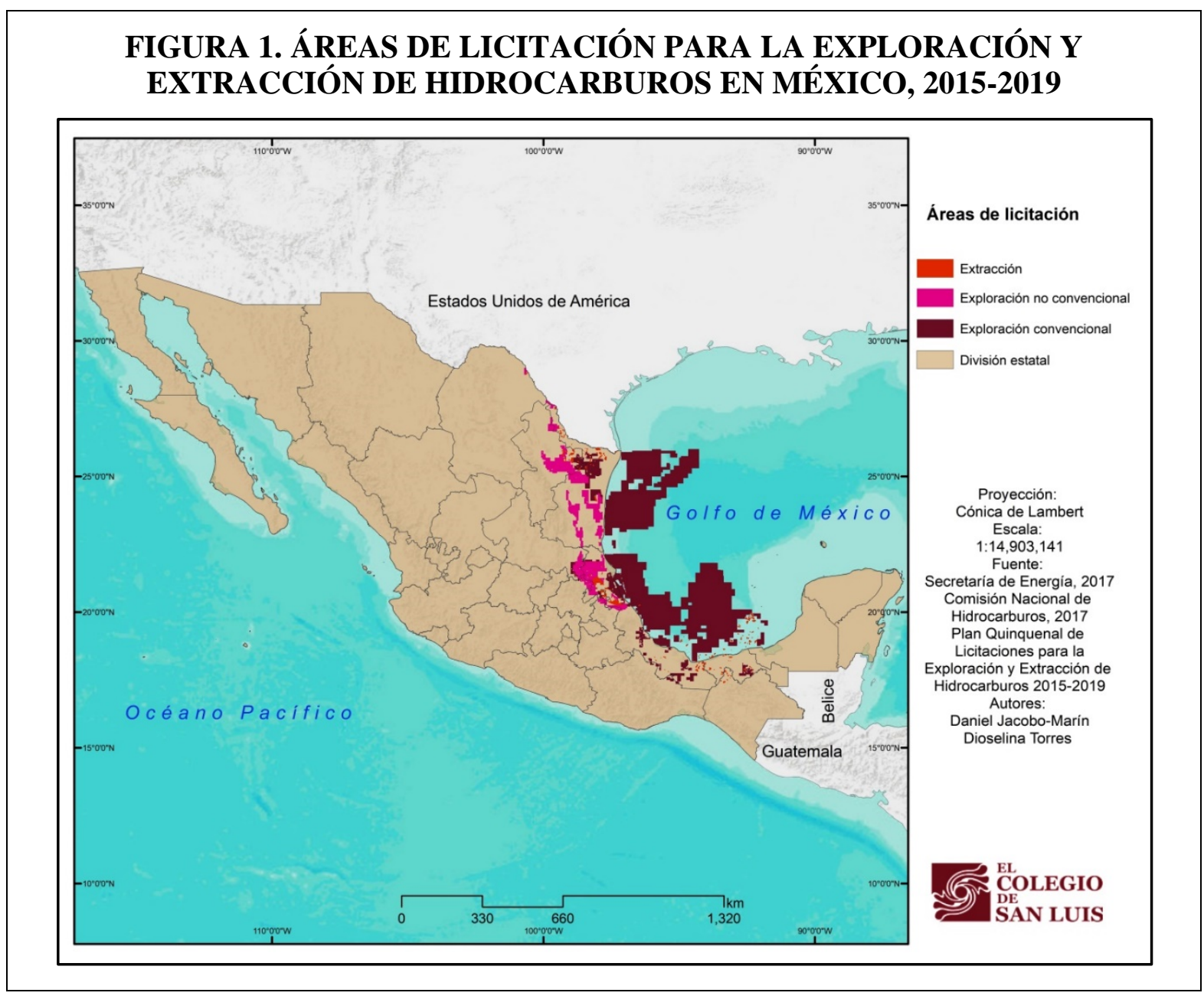

\section{REGULACIÓN DE LA FRACTURA HIDRÁULICA EN MÉXICO Y PERSPECTIVA COMPARADA CON EL MARCO EUROPEO}

La modificación del modelo en materia de hidrocarburos generó coyunturas políticas y jurídicas que apuntalaron la industria energética. En términos de la regulación de la técnica conocida como fractura hidráulica (fracking) dos aspectos son especialmente relevantes: la selección prospectiva de yacimientos en el Plan quinquenal de licitaciones ${ }^{17}$ y la concesión de los derechos de agua necesarios para el proceso de estimulación artificial.

La reglamentación de la reforma energética publicada el 11 de agosto de 2014 refrendó el orden de prelación para el aprovechamiento del suelo en México. Para este fin, se generó un mecanismo de concordancia entre la Ley de Hidrocarburos y la Ley Minera, de modo que se otorgaron facultades a la Secretaría de Economía para que verifique si la superficie en la que se solicita una concesión minera está sujeta a las actividades de extracción de energéticos o de transmisión de energía eléctrica. ${ }^{18}$ Aunque se prevé la

\footnotetext{
${ }^{17}$ Véase: SECRETARÍA DE ENERGÍA (2017), pp. 21 y ss.

${ }^{18}$ JACOBO-MARÍN, (2019), pp. 132-134.
} 
coexistencia de las actividades cuando sea técnicamente posible, las asignaciones de hidrocarburos tienen preferencia sobre las licencias para beneficiar minerales. ${ }^{19}$

Esta situación fue posible debido a la ausencia de la Ley General de Aguas (LGA), un ordenamiento que debió ser emitido en términos de la reforma al artículo $4^{\circ}$ constitucional publicada el 8 de febrero de 2012. Por disposición del decreto reformatorio el Congreso de la Unión contaba con un plazo de 360 días para emitir la LGA, pero hasta el momento no ha sido aprobada. ${ }^{20}$ Esta coyuntura legislativa mantiene vigente la Ley de Aguas Nacionales (LAN), promulgada el 1 de diciembre de 1992 en el marco de los compromisos de adecuación normativa requeridos para el Estado mexicano, previos a la entrada en vigor del TLCAN. ${ }^{21}$

Dicha coyuntura también posibilitó las modificaciones normativas que vigorizaron el sector energético; por este motivo, la LAN fue usada como una plataforma jurídica en vías de abrogación para reglamentar, a través de las reformas sobre hidrocarburos, disposiciones que permiten el aprovechamiento preferente del agua para la explotación de los recursos fósiles ubicados en el subsuelo. ${ }^{22}$ Ahora bien, la reglamentación de la fractura hidráulica no transitó por el proceso legislativo ordinario, se prefirió la emisión de lineamientos administrativos generales por parte de las entidades gubernamentales encargadas de la gestión de las aguas nacionales y de la seguridad industrial en materia de hidrocarburos; con esta situación se evitó el debate parlamentario y las controversias jurisdiccionales que generaría la eventual aprobación de la técnica.

El 16 de marzo de 2017 la Agencia Nacional de Seguridad Industrial y de Protección al Medio Ambiente del Sector Hidrocarburos (ASEA) ${ }^{23}$ publicó en el DOF los Lineamientos en materia de seguridad industrial, seguridad operativa y protección al medio ambiente para realizar las actividades de exploración y extracción de hidrocarburos en yacimientos no convencionales en tierra. Los lineamientos contienen los requisitos para ejecutar actividades de perforación de pozos, fracturamiento hidráulico, establecimiento de equipos, manejo de fluidos de perforación, pruebas de conducción y recolección de hidrocarburos no convencionales en tierra. Adicionalmente, el decreto contiene una lista de las sustancias susceptibles de extraerse, que incluye aceite en lutitas, aceites pesados y extra

\footnotetext{
${ }^{19}$ De acuerdo con la Ley Minera, la exploración, la explotación y el beneficio de los minerales son de utilidad pública y de aprovechamiento preferente sobre cualquier otro uso del terreno (artículo 6, párrafo primero). La edición vigente de la Ley Minera se publicó en el DOF el 26 de julio de 1992 y, mediante la reforma energética, se aprobaron modificaciones el 11 de agosto de 2014.

${ }^{20}$ La reforma aprobada el 8 de febrero de 2012 incorporó el derecho humano al agua y el saneamiento en el texto constitucional, al artículo $4^{\circ}$ se agregó un párrafo que indica: “Toda persona tiene derecho al acceso, disposición y saneamiento de agua para consumo personal y doméstico en forma suficiente, salubre, aceptable y asequible [...]”. DIARIO OFICIAL DE LA FEDERACIÓN (2012), Decreto por el que se declara reformado el párrafo quinto y se adiciona un párrafo sexto, recorriéndose en su orden los subsecuentes, al artículo 40 de la Constitución Política de los Estados Unidos Mexicanos, México, 8 de febrero.

${ }^{21}$ La Ley de Aguas Nacionales fue reformada posteriormente, el 29 de abril de 2004, bajo el argumento de la descentralización administrativa, durante el gobierno de Vicente Fox Quesada.

22 JACOBO-MARÍN, D. (2016), Análisis de concordancia entre la Ley de Hidrocarburos y la Ley Minera con la Iniciativa Ciudadana de Ley General de Aguas, Coordinadora Nacional Agua para Todos, Agua para la Vida, México.

${ }^{23}$ La Agencia Nacional de Seguridad Industrial y de Protección al Medio Ambiente del Sector Hidrocarburos (ASEA) fue creada por el decreto de reforma constitucional el 20 de diciembre de 2013, véase la tabla 2.
}

Revista de Estudios Jurídicos nº 20/2020 (Segunda Época)

ISSN-e 2340-5066. Universidad de Jaén (España)

Versión electrónica: rej.ujaen.es 
pesados, gas en lutitas, gas en rocas compactadas, hidratos de metano y gas en vetas de carbón. ${ }^{24}$

Por otro lado, el 30 de agosto de 2017 la Comisión Nacional del Agua (CONAGUA) ${ }^{25}$ divulgó los Lineamientos para la protección y conservación de las aguas nacionales en actividades de exploración y extracción de hidrocarburos en yacimientos no convencionales. Este dispositivo permite la transmisión de derechos otorgados previamente para otros usos, la concesión de aguas marinas desalinizadas y la reserva de aguas residuales no comprometidas para el riego. ${ }^{26}$ Los lineamientos emplean la seguridad operativa, la protección de las aguas y la conservación del medio ambiente como narrativas eufemísticas; mediante una lectura detallada de los decretos se observa que reproducen el esquema de aprovechamiento preferente del agua para las actividades industriales, la ocupación temporal del suelo y la perforación de pozos para obtener hidrocarburos.

En el ámbito europeo, un conjunto de Directivas permite analizar el caso de regulación de la fractura hidráulica, en términos del mercado energético y las implicaciones del uso de esta técnica para la calidad de las aguas subterráneas, los ecosistemas y la salud humana. En tal sentido, el artículo 4 del Tratado de Funcionamiento de la Unión Europea (TFUE) establece la competencia compartida con los Estados miembros en materia de medio ambiente y energía, de forma específica, el Título XXI está dedicado a la energía y tiene por objetivo garantizar la operación del mercado energético y la seguridad en el abastecimiento de la Unión Europea (UE). La facultad para legislar en materia de medio ambiente está regulada por el artículo 191 del TFUE, cuya política regional se basa en los principios de cautela y de acción preventiva, en el principio de corrección de los atentados al medio ambiente (preferentemente en la fuente misma), y en el principio de quien contamina paga.

La armonización normativa necesaria para la protección ambiental debe incluir una cláusula de salvaguardia que autorice a los Estados miembros a adoptar, por motivos medioambientales no económicos, medidas provisionales sometidas a un procedimiento de control de la UE. ${ }^{27}$ La delimitación de competencias que se ubica en el artículo 5 del Tratado de la Unión Europea (TUE) se rige por el principio de atribución y, el ejercicio de

${ }^{24}$ DIARIO OFICIAL DE LA FEDERACIÓN (2017), Disposiciones administrativas de carácter general que establecen los lineamientos en materia de seguridad industrial, seguridad operativa y protección al medio ambiente para realizar las actividades de exploración y extracción de hidrocarburos en yacimientos no convencionales en tierra, México, 16 de marzo.

${ }^{25}$ La Comisión Nacional del Agua es el órgano administrativo desconcentrado de la Secretaría de Medio Ambiente y Recursos Naturales, que tiene funciones de derecho público en materia de aguas nacionales y sus bienes públicos inherentes. Este órgano cuenta con autonomía técnica, ejecutiva, administrativa, presupuestal y de gestión (véanse los artículos 3 fracción XII y 9 de la Ley de Aguas Nacionales). Fue creada el 16 de enero de 1989, véase: DIARIO OFICIAL DE LA FEDERACIÓN (1989), Decreto por el que crea la Comisión Nacional del Agua como órgano administrativo desconcentrado de la Secretaría de Agricultura y Recursos Hidráulicos, México, 16 de enero. Por otro lado, de acuerdo con el artículo 115 constitucional, los servicios públicos de agua potable, alcantarillado y saneamiento están a cargo de los municipios.

${ }^{26}$ DIARIO OFICIAL DE LA FEDERACIÓN (2017), Lineamientos para la protección y conservación de las aguas nacionales en actividades de exploración y extracción de hidrocarburos en yacimientos no convencionales, México, 30 de agosto.

27 DIARIO OFICIAL DE LA UNIÓN EUROPEA (2010), Versión consolidada del Tratado de Funcionamiento de la Unión Europea, (C 83/47). 
las competencias de la UE, se orienta por los principios de subsidiariedad y de proporcionalidad. ${ }^{28}$ El principio de atribución indica que la UE actúa dentro de los límites de las competencias que le atribuyen los Estados miembros para lograr los objetivos que determinan los tratados. En virtud del principio de subsidiaridad, en los ámbitos que no sean de su competencia exclusiva, la UE interviene sólo en caso de que los objetivos de la acción pretendida no puedan ser alcanzados por los miembros a escala local o regional. ${ }^{29}$ En virtud del principio de proporcionalidad, el contenido y la forma de la acción de la UE no excederán de lo necesario para alcanzar los objetivos de los tratados.

La exploración y extracción de recursos no convencionales en Europa, en particular el gas shale, se ha convertido en uno de los temas de mayor relevancia y presencia dentro del Parlamento. Debido a la preocupación de los Estados miembros de la UE y de la ciudadanía sobre los impactos generados por el fracking, a finales del año 2010 se había llegado a la conclusión de que era indispensable que las autoridades europeas implementaran medidas para la obtención de recursos fósiles de forma segura, dilucidando las cuestiones en torno a los riesgos potenciales para la salud humana, el ambiente y la necesidad de generar un marco regulatorio que abordara la nueva técnica. ${ }^{30}$

Por otro lado, la diversidad de opiniones relacionadas con proyectos potenciales o en marcha, así como la experiencia previa en la regulación de industrias extractivas han derivado en las diferencias regionales respecto a la narrativa, aprobación y reglamentación del fracking. ${ }^{31}$ De tal modo, el marco regulador de la UE optó por una recomendación y no por una comunicación, que de acuerdo con el artículo 288 del TFUE no tiene fuerza vinculante, lo que se ha interpretado como una norma soft law debido a las características particulares de cada yacimiento de gas y las variables dependientes asociadas a la formación geológica, la ubicación de la reserva, los químicos que deberán emplearse, entre otros. $^{32}$

La Directiva 2011/92/UE establece los principios generales de evaluación de las repercusiones sobre el medio ambiente a fin de completar y coordinar los procedimientos de autorización de los proyectos públicos y privados que puedan tener un impacto importante sobre el medio ambiente. Sólo debe concederse autorización a estos proyectos después de una evaluación, tomando como base la información proporcionada por el promotor y eventualmente completada por las autoridades y por el público al que pueda interesar el proyecto. Esta Directiva recomienda la fijación de umbrales o criterios para estudiar los proyectos caso por caso, para determinar cuáles han de someterse a una

\footnotetext{
${ }^{28}$ DIARIO OFICIAL DE LA UNIÓN EUROPEA (2012), Versión consolidada del Tratado de la Unión Europea, (C 326/13).

${ }^{29}$ Las instituciones de la UE aplican el principio de subsidiariedad de conformidad con el Protocolo sobre la aplicación de los principios de subsidiariedad y proporcionalidad. Los Parlamentos nacionales velan por el respeto del principio de subsidiariedad con arreglo al procedimiento establecido en el mencionado Protocolo. Véase: DIARIO OFICIAL DE LA UNIÓN EUROPEA (2012), p. 6, (artículo 5, apartado 3).

${ }^{30}$ VALDÉS AGUIRRE, C. L. (2018), Aplicación del principio precautorio a la fractura hidráulica: análisis multidisciplinario del marco regulador en los Estados Unidos, México y la Unión Europea, Tesis Doctoral, Universidad Complutense, Madrid, pp. 231 y ss.

${ }^{31}$ CANTONI, R., et al. (2018), "Shale Tales: Politics of Knowledge and Promises in Europe's Shale Gas Discourses", The Extractive Industries and Society, vol, 5, n 4, pp. 535-546.

32 FLEMING, R. (2017), “The New German Fracking Package”, Journal of Energy \& Natural Resources Law, vol. 35, no 3, pp. 293-316.
} 
evaluación en función de la relevancia de sus repercusiones sobre el medio ambiente, de conformidad con el principio de subsidiariedad. ${ }^{33}$

El anexo I de la Directiva 2011/92/UE describe los proyectos contemplados en el apartado 1 del artículo 4, que incluye refinerías de petróleo bruto e instalaciones de gasificación y de licuefacción de al menos 500 toneladas de carbón o de pizarra bituminosa al día. El anexo II detalla los proyectos contemplados en el apartado 2 del citado artículo, que incluye los de la industria extractiva, referibles a las instalaciones industriales en el exterior para la extracción de carbón, petróleo, gas natural, minerales y pizarras bituminosas. El apartado 1 del artículo 4 establece que los proyectos enumerados en el anexo I serán objeto de evaluación de conformidad con lo establecido en los artículos 5 a 10 de la Directiva. Para el caso de los proyectos enumerados en el anexo II, los Estados miembros determinan si el proyecto será objeto de una evaluación de conformidad con lo establecido en los artículos 5 a 10, mediante un estudio caso por caso o mediante umbrales o criterios establecidos por cada Estado. ${ }^{34}$

En el mismo sentido, la Directiva 2006/21/CE establece medidas, procedimientos y orientaciones para prevenir y reducir los efectos adversos sobre las aguas, el aire, el suelo, la fauna, la flora y el paisaje, y los riesgos para la salud humana derivados de la gestión de los residuos de las industrias extractivas; tales como los residuos de extracción y tratamiento, la roca estéril, los terrenos de recubrimiento y la tierra vegetal siempre que constituyan residuos definidos por la Directiva 75/442/CEE. En el contexto de los efectos potenciales de la fractura hidráulica, los Estados miembros deben obligar a las entidades que participan en las industrias extractivas a aplicar las mejores técnicas disponibles de seguimiento y control de la gestión para prevenir la contaminación del agua y el suelo, e identificar cualquier efecto adverso que sus instalaciones de residuos puedan tener sobre el medio ambiente y la salud de las personas. ${ }^{35}$

Con el fin de reducir al mínimo la contaminación del agua, el vertido de residuos en cualquier masa de agua debe efectuarse de acuerdo con las disposiciones de la Directiva 2000/60/CE, de 23 de octubre de 2000, por la que se establece un marco comunitario de actuación en el ámbito de la política de aguas. Ahora bien, ninguno de los planes y disposiciones de la Directiva 2000/60/CE contienen medidas específicas sobre los residuos producidos por la industria de gas no convencional, no obstante que los desechos generados por los procesos de extracción de gas de esquisto mediante fracking necesitan una regulación específica, ya que los desechos, especialmente el agua contaminada, son más tóxicos y peligrosos y, por lo tanto, difíciles de recolectar y limpiar. ${ }^{36}$

La Directiva 2000/60/CE establece un marco para la protección de las aguas superficiales continentales, las aguas de transición, las aguas costeras y las aguas subterráneas, que prevenga su deterioro y garantice la reducción progresiva de los vertidos,

\footnotetext{
${ }^{33}$ DIARIO OFICIAL DE LA UNIÓN EUROPEA (2011), Directiva 2011/92/UE del Parlamento Europeo y del Consejo, de 13 de diciembre de 2011, relativa a la evaluación de las repercusiones de determinados proyectos públicos y privados sobre el medio ambiente, (L 26/1).

${ }^{34}$ DIARIO OFICIAL DE LA UNIÓN EUROPEA (2011), p. 4, (artículo 4, apartados 1 y 2).

${ }_{35}$ DIARIO OFICIAL DE LA UNIÓN EUROPEA (2006), Directiva 2006/21/CE del Parlamento Europeo y del Consejo, de 15 de marzo de 2006, sobre la gestión de los residuos de industrias extractivas y por la que se modifica la Directiva 2004/35/CE, (L 102/15).

${ }^{36}$ VALDÉS AGUIRRE, (2018), p. 238.
} 
las emisiones y las pérdidas de sustancias peligrosas prioritarias. De forma específica, el artículo 11 inciso j de la Directiva 2000/60/CE indica a los Estados un programa de medidas que puedan derivar de la legislación nacional con arreglo al artículo 5, con el fin de alcanzar los objetivos establecidos en el artículo 4, relativos a las medidas específicas en los planes hidrológicos de cuenca. Se estableció también la prohibición de vertidos directos de contaminantes en las aguas subterráneas. ${ }^{37}$ Sin embargo, los Estados miembros pueden autorizar la inyección de aguas que contengan sustancias resultantes de las operaciones de exploración y extracción de hidrocarburos o actividades mineras, así como la inyección de aguas por razones técnicas en formaciones geológicas de las que se hayan extraído hidrocarburos u otras sustancias, o en formaciones geológicas que por razones naturales no sean apropiadas, de manera permanente, para otros fines. ${ }^{38}$

\section{PANORAMA MEXICANO SOBRE LA FRACTURA HIDRÁULICA FRENTE AL PRINCIPIO PRECAUTORIO}

Durante la segunda mitad del siglo XIX el aprovechamiento del gas metano se convirtió en un área de creciente inversión para la industria energética en la costa este de EUA, que fue desarrollándose a la par de la extracción del petróleo. Concluida la Segunda Guerra Mundial, la industria del gas remozó con el tendido kilométrico de gasoductos que facilitaron la entrega en los centros de producción y consumo (polos industriales y zonas urbanas). Posteriormente, la posibilidad de extraer gas de lutitas mediante la aplicación de técnicas complejas cristalizó las expectativas de producir a gran escala para el mercado global. Este modelo de aprovechamiento intensivo fue impulsado especialmente desde fines de la década de 1980 y se conoce como revolución del gas. Fue matizado bajo el discurso de garantizar el abasto interno y, eventualmente, alcanzar la seguridad energética. ${ }^{39}$

Las técnicas de obtención de energéticos que emplean fórmulas mezcladas con agua generan un profundo debate. El gas de lutitas (shale gas en inglés) es un hidrocarburo no convencional que se ubica en yacimientos compuestos por rocas de baja permeabilidad,

${ }^{37}$ DIARIO OFICIAL DE LA UNIÓN EUROPEA (2000), Directiva 2000/60/CE del Parlamento Europeo y del Consejo, de 23 de octubre de 2000, por la que se establece un marco comunitario de actuación en el ámbito de la política de aguas, (L 327/1).

${ }^{38}$ En España, el Real Decreto 849/1986 regula los bienes que integran el dominio público hidráulico y, de manera particular, indica que el dominio público de los acuíferos o formaciones geológicas por las que circulan aguas subterráneas, se entiende sin perjuicio de que el propietario del fundo pueda realizar cualquier obra que no tenga por finalidad la extracción o aprovechamiento del agua ni perturbe su régimen ni deteriore su calidad. El Reglamento también se refiere a la determinación de perímetros de protección de los acuíferos en la realización de obras de infraestructura, extracción de áridos y otras actividades o instalaciones que pudieran afectarlos, en los que es necesaria la autorización del Organismo de cuenca, incluyendo las actividades industriales, como el almacenamiento, transporte y tratamiento de hidrocarburos líquidos o gaseosos, de acuerdo con el inciso d del artículo 173. Véase: BOLETÍN OFICIAL DEL ESTADO (1986), Real Decreto 849/1986, de 11 de abril, por el que se aprueba el Reglamento del Dominio Público Hidráulico, que desarrolla los títulos preliminares, I, IV, V, VI y VII de la Ley 29/1985, de 2 de agosto, de Aguas. Madrid, Ministerio de Obras Públicas y Urbanismo, BOE-A-1986-10638, núm. 103, 30 de abril.

${ }^{39}$ JACOBO-MARÍN, (2019), pp. 138 y ss. 
lo que impide su ascenso a la superficie. ${ }^{40}$ Los yacimientos convencionales se ubican entre una roca porosa (permeable) y una trampa rocosa impermeable que evitan la fuga de los hidrocarburos; los no convencionales se alojan en la roca madre (de baja porosidad) y, al no depender de una trampa para su acumulación, requieren estimulación artificial para explotarlos. ${ }^{41}$

La fractura hidráulica es una técnica de estimulación que pretende la perforación de pozos (verticales y horizontales) cementados y entubados, con el objetivo de generar canales de conductividad mediante la inyección de agua a alta presión (mezclada con arena y compuestos químicos). Esto permite que el agua supere la resistencia de la roca y la fracture, de modo que los hidrocarburos son captados en el yacimiento y luego se hacen fluir hacia la superficie. De forma general, los pozos se perforan verticalmente hacia los yacimientos; en otros procesos, una vez alcanzada la profundidad deseada (entre 1,000 y 2,500 metros), la perforadora gira 90 grados en sentido horizontal para generar fisuras. ${ }^{42}$

Algunas investigaciones sugieren que la perforación de investigación es el único medio confiable para determinar la presencia de hidrocarburos y la viabilidad de su extracción; se trata de una etapa de evaluación prospectiva en la que se analizan datos geológicos, geoquímicos y sísmicos. ${ }^{43}$ Se estima que esta técnica consume en promedio 21 millones de litros de agua por etapa de fracturación, se requieren varias etapas para lograr que se libere el gas atrapado en la porosidad de la roca. De la mezcla de compuestos químicos que se inyectan con el agua, se han identificado 750 sustancias, entre las cuales, 29 son posibles cancerígenos como benceno, naftaleno, éteres, glicoles y aromáticos policíclicos. ${ }^{44}$

La composición del fluido de fracturación es variable y se desarrolla en función de las características del campo donde se aplicará; las fórmulas se encuentran protegidas por la legislación corporativa estadounidense bajo la figura de secreto industrial. Este esquema de opacidad exhibe que la ambigüedad técnico-legal es aprovechada por los operadores del sector industrial energético para apuntalar las actividades extractivas. Adicionalmente, la reglamentación ex profeso fortalece el esquema de incertidumbre sobre el contenido y la cantidad de compuestos tóxicos en el fluido de fracturación y obstaculiza el análisis integral de la composición química, los efectos sinérgicos de la mezcla y las interacciones físico-químicas con la roca. ${ }^{45}$

Aunque la industria de perforación alega que la distancia entre los acuíferos y las reservas de hidrocarburos reduce los riesgos potenciales, se han documentado numerosas repercusiones socio-ambientales, incluidas la contaminación de aguas superficiales, la

\footnotetext{
${ }^{40}$ Las lutitas son rocas de grano fino que se forman a partir de la compactación de partículas de limo y arcilla. Se ha señalado la necesidad de que las lutitas sean esquistosas para generar gas; los esquistos son deformaciones metamórficas de las lutitas, por ello, algunos textos le denominan gas de esquisto.

${ }^{41}$ LEES, Z. (2012), "Anticipated Harm, Precautionary Regulation and Hydraulic Fracturing”, Vermont Journal of Environmental Law, vol. 13, pp. 575-612.

${ }^{42}$ GOLDEN, J. y WISEMAN, H. (2015), "The Fracking Revolution: Shale Gas as a Case Study in Innovation Policy”, Emory Law Journal, vol. 64, nº 4, pp. 955-1040.

${ }^{43}$ GOLDEN y WISEMAN (2015), pp. 990-994.

${ }^{44}$ CARBONELL LEÓN, M. N. (2017), "Fracturación hidráulica y principio precautorio", Reforma en materia de hidrocarburos. Análisis jurídicos, sociales y ambientales en prospectiva, IIJ-UNAM-Universidad Autónoma de Tamaulipas, México, p. 89.

${ }^{45}$ JACOBO-MARÍN, (2019), p. 139.
}

Revista de Estudios Jurídicos nº 20/2020 (Segunda Época)

ISSN-e 2340-5066. Universidad de Jaén (España)

Versión electrónica: rej.ujaen.es 
emisión de gas metano (cuya contribución al efecto invernadero es superior a la generada por el dióxido de carbono), la sismicidad inducida y la migración de sustancias tóxicas hacia las aguas subterráneas. ${ }^{46}$

La CNH informó públicamente que hasta agosto de 2019 se habían perforado 30,558 pozos en la zona terrestre de México, de los que sólo se cuenta con información de perforación de 19,563. Con base en la información recopilada desde 1994 la CNH identificó actividad de fracturación hidráulica en 8,457 pozos (es decir, el 43\% del total de los pozos terrestres), aunque sólo 27 de éstos habían sido perforados con objetivos no convencionales. De los 8,457 pozos se han recuperado 1,476 millones de barriles de aceite y 12,038 millones de pies cúbicos de gas, que corresponden a 3,884 millones de barriles de petróleo crudo equivalente, lo que representa el $7 \%$ de la producción histórica del país. ${ }^{47}$

El informe muestra el panorama de extracción de hidrocarburos no convencionales mediante fracking y los estados donde se realiza: Tamaulipas (2,734 pozos en 128 campos), Veracruz (2,270 pozos en 81 campos), Nuevo León (1,776 pozos en 51 campos), Puebla (1,390 pozos en 11 campos), Tabasco (224 pozos en 50 campos), Chiapas (37 pozos en 15 campos) y Coahuila (26 pozos en 8 campos). ${ }^{48}$ Los datos coinciden con las apreciaciones de la Agencia Internacional de Energía (AIE), organismo que estimó las reservas de gas de México entre las 10 más grandes del mundo. La mayor concentración prospectiva se documentó en la cuenca de Burgos, un yacimiento transfronterizo ubicado entre Texas (EUA) y los estados mexicanos de Coahuila, Nuevo León y Tamaulipas.

De esta manera, la región noreste de México se revela como un espacio estratégico de extracción para la industria energética (véase la figura 1). El panorama extractivo aumenta con la escala: considérese la frontera entre México y EUA y, con ello, las dicotomías tecnológicas, jurídicas y políticas entre los dos países para aprovechar los bienes del subsuelo. Un aspecto relevante, en términos de los instrumentos internacionales y de los órdenes constitucionales, es el uso de aguas superficiales de cauces binacionales y de las aguas subterráneas transfronterizas. ${ }^{49}$

La fractura hidráulica se impulsa por el discurso que la considera el bastión para atraer los capitales trasnacionales. Sin embargo, el uso de esta técnica se perfila como un mecanismo de despojo hídrico por dos razones: primera, por la competencia asimétrica por el agua en tierras de propiedad social colectiva y, segunda, porque la técnica se caracteriza por la contaminación del líquido, lo que impide que otros usuarios puedan aprovecharlo. ${ }^{50}$ Es decir, se reduce el acceso a agua limpia derivado de su uso en los ciclos de producción

\footnotetext{
${ }^{46}$ GAGNON, G. A., et al. (2016). "Impacts of hydraulic fracturing on water quality: a review of literature, regulatory frameworks and an analysis of information gaps”, Environmental Reviews, vol. 24, n 2, pp. 122126.

${ }^{47}$ COMISIÓN NACIONAL DE HIDROCARBUROS (2019), “El fracturamiento hidráulico es una técnica de producción de uso intensivo en campos de gas”, informe, 20 de agosto, México. [Disponible en: https://hidrocarburos.gob.mx/media/2792/pozos-con-fracturamiento_200819.pdf]

${ }^{48}$ COMISIÓN NACIONAL DE HIDROCARBUROS (2019).

49 HATCH KURI, G. (2018), "Fracking en el Acuífero Transfronterizo Edwards-Trinity-El Burro: implicaciones y daños ambientales transfronterizos”, Investigaciones Geográficas, nº 96, pp. 4-16.

50 ISCH, E. (2011), “La contaminación del agua como proceso de acumulación”, Justicia hídrica. Acumulación, conflicto y acción social, Pontificia Universidad Católica del Perú-Instituto de Estudios Peruanos-Alianza Internacional Justicia Hídrica, Lima, p. 98.
}

Revista de Estudios Jurídicos no 20/2020 (Segunda Época)

ISSN-e 2340-5066. Universidad de Jaén (España)

Versión electrónica: rej.ujaen.es 
industrial y la utilización de sustancias tóxicas mezcladas con el agua que se liberan en el entorno. ${ }^{51}$

En tal sentido, ninguno de los lineamientos expedidos en México contempla el principio de precaución o medidas específicas para su aplicación. La Carta Mundial de la Naturaleza (28 de octubre de 1982) precisó este principio con tres enunciados básicos: 1) evitar las actividades que puedan causar daños irreversibles a la naturaleza, 2) las actividades que puedan entrañar peligro serán precedidas por un examen a fondo y, 3) las actividades no se llevarán a cabo cuando no se conozcan cabalmente sus posibles efectos perjudiciales.

En el mismo contexto, la Declaración de Río sobre el Medio Ambiente y el Desarrollo (14 de junio de 1992) señala: "cuando haya peligro de daño grave o irreversible, la falta de certeza científica absoluta no deberá utilizarse como razón para postergar la adopción de medidas [...] para impedir la degradación del medio ambiente” (principio 15). El Convenio de Estocolmo sobre Contaminantes Orgánicos Persistentes (23 de mayo de 2001) asume el criterio de precaución como base para la protección del medio ambiente y la salud humana. Este instrumento internacional fue ratificado por el Estado mexicano y, por lo tanto, forma parte del bloque de convencionalidad de acuerdo con la reforma constitucional en derechos humanos de 10 de junio de 2011, es decir, constituye un ordenamiento vinculante que debe emplearse para salvaguardar los derechos ambientales y los derechos de la naturaleza.

Pese a las previsiones de los instrumentos internacionales, una decisión gubernamental le dio alcance a los lineamientos: el 6 de junio de 2018 el gobierno federal decretó el levantamiento de vedas y el establecimiento de reservas de aguas nacionales. ${ }^{52}$ Mediante la publicación de 10 decretos se suprimieron vedas de agua superficial en 9 de las regiones hidrológicas más importantes del país: Pánuco, Lerma-Santiago, Costa Grande y Costa Chica de Guerrero, San Fernando-Soto La Marina, Papaloapan, Ameca, Costa de Jalisco y Grijalva-Usumacinta. La supresión de las vedas permitiría asegurar el agua requerida para las asignaciones energéticas que pretenden obtener hidrocarburos no convencionales.

No obstante, la narrativa de los lineamientos administrativos, el artículo 416 del Código Penal Federal prohíbe la infiltración de aguas residuales, líquidos químicos o contaminantes en el subsuelo que causen daño a la calidad del agua y el ecosistema. De este modo, la premura gubernamental para reglamentar las técnicas de extracción generó un conflicto normativo con las disposiciones protectoras del agua subterránea que se mantiene irresuelto. ${ }^{53}$

\footnotetext{
${ }^{51}$ LEIFSEN, E. (2017), "Wasteland by design: Dispossession by contamination and the struggle for water justice in the Ecuadorian Amazon”, The Extractive Industries and Society, vol. 4, no 2, pp. 344-351.

${ }^{52}$ Las zonas de veda son áreas específicas de las regiones hidrológicas, cuencas hidrológicas o acuíferos, en las cuales no se autorizan aprovechamientos de agua adicionales a los establecidos y éstos se controlan mediante reglamentos específicos, en virtud del deterioro del agua en cantidad o calidad, por la afectación a la sustentabilidad hidrológica, o por el daño a cuerpos de agua superficiales o subterráneos (Ley de Aguas Nacionales, artículo 3 fracción LXV).

53 JACOBO-MARÍN, (2016).
} 


\section{LOS DERECHOS COMUNITARIOS DE AGUA EN EL CONTEXTO DEL NUEVO MARCO LEGAL ENERGÉTICO}

El artículo 27 constitucional configura el criterio patrimonial de las aguas nacionales; según dicho criterio, las aguas son propiedad originaria de la nación y de ellas tiene el dominio inalienable e imprescriptible. La nación puede transmitir el dominio de las aguas a los particulares, constituyendo la propiedad privada, mediante una concesión para la explotación, el uso o el aprovechamiento, de acuerdo con los párrafos primero y sexto del referido artículo 27. La Ley de Aguas Nacionales (LAN) publicada en 1992, es el ordenamiento reglamentario en materia de derechos de agua que se desarrolló a partir de la base constitucional. ${ }^{54}$ La LAN se expidió en el marco de los requerimientos de adecuación normativa exigidos por la entrada en vigor del TLCAN, de este modo, la LAN suplió a la Ley Federal de Aguas vigente desde 1972.

Los derechos de agua son las convenciones formales o tradicionales que certifican los aprovechamientos que el Estado o la autoridad del agua otorga para diversos usos. En México, los derechos de agua oficiales se asumen bajo dos figuras jurídicas: la concesión y la asignación. La concesión es el título que otorga la prerrogativa de usar un volumen específico de agua, vinculado con la producción y la obtención de lucros definidos (industrial, comercial, agrícola, recreativo). La asignación es el título cuyo fin es satisfacer los usos doméstico y público-urbano, que se otorga a los municipios, los estados y la Ciudad de México. ${ }^{55}$

El orden de prelación de los usos del agua en México está definido en el artículo XV transitorio de la LAN, de acuerdo con este dispositivo, la prioridad de los usos para concesión y asignación de aguas nacionales será de la siguiente manera: 1) doméstico, 2) público-urbano, 3) pecuario, 4) agrícola, 5) acuacultura, 6) usos para la conservación ecológica o uso ambiental, 7) generación de energía eléctrica para uso público, 8) industrial, 9) generación de energía eléctrica para uso privado, 10) lavado y entarquinamiento de terrenos, 11) uso para turismo, recreación y fines terapéuticos, 12) uso múltiple y 13) otros usos. Este artículo, modificado el 24 de marzo de 2016, no contempla la infiltración de aguas residuales tratadas para la recarga artificial de acuíferos ni la inyección de aguas de cualquiera otra naturaleza (marinas desalinizadas o las reservadas no comprometidas para el riego) con fines de extracción de hidrocarburos no convencionales, como lo indican los lineamientos expedidos por la CONAGUA en agosto de 2017. ${ }^{56}$

De acuerdo con el artículo 24 de la LAN las concesiones de aguas nacionales tienen un término de treinta años, estimando el orden de prelación del uso específico de que se trate, las condiciones de la fuente de suministro y las expectativas de crecimiento de otros usos. Los títulos de concesión son prorrogables por términos iguales (treinta años),

\footnotetext{
${ }^{54}$ La compilación más completa sobre la legislación de aguas en México puede consultarse en: LANZ CÁRDENAS, J. T. (1982), Legislación de aguas en México. Estudio histórico-legislativo de 1521-1981, 4 vols., Gobierno del Estado de Tabasco, Villahermosa.

55 JACOBO-MARÍN, D. (2017), "Si el agua es poca, a la ciudad le toca. Demanda urbana y derechos de agua en la ciudad de San Luis Potosí, México”, (In) Justicia Hídrica. Resistencias y Alternativas en América Latina, n 3, CBC-Alianza Internacional Justicia Hídrica, Medellín, pp. 61-67.

${ }^{56}$ DIARIO OFICIAL DE LA FEDERACIÓN (2016), Decreto por el que se reforman y adicionan diversas disposiciones de la Ley de Aguas Nacionales, México, 24 de marzo.
}

Revista de Estudios Jurídicos nº 20/2020 (Segunda Época)

ISSN-e 2340-5066. Universidad de Jaén (España)

Versión electrónica: rej.ujaen.es 
siempre que se soliciten dentro de los últimos cinco años. En México, los derechos contenidos en los títulos de concesión se consideran parte de los derechos patrimoniales de su titular, por lo que pueden transmitirse inter vivos o por sucesión hereditaria. La extracción y aprovechamiento de los materiales pétreos localizados dentro de los cauces son también susceptibles de concesionarse, debido a que forman parte de los llamados “bienes públicos inherentes a las aguas nacionales” de acuerdo con el artículo 24 de la LAN. La concesión de aguas nacionales se tramita y se otorga mediante los mecanismos especificados en este ordenamiento. El solicitante debe exhibir los documentos que acrediten la propiedad o posesión del inmueble donde serán extraídas las aguas, la constitución de servidumbres de paso, la Manifestación de Impacto Ambiental (MIA), la memoria técnica de los planos y obras de infraestructura y la documentación técnica en términos del volumen solicitado. ${ }^{57}$

En la doctrina clásica se ha ensayado la hipótesis relativa a que los derechos de agua son de naturaleza jurídica opuesta a los derechos de propiedad y posesión de la tierra y, bajo ese esquema, la legislación ha mantenido una definición normativa y procedimental para cada uno, mediante la siguiente fórmula: las aguas son públicas y excepcionalmente privadas, en tanto que las tierras son privadas y excepcionalmente públicas. ${ }^{58}$ Este enfoque supone que las tierras y las aguas se encuentran separadas y, por lo tanto, deben ser reglamentadas en ámbitos disciplinarios autónomos con escaso perímetro de contacto. Lo que muestra la realidad es que mantienen una relación estrecha y dinámica, alimentada por la reproducción social y la organización comunitaria.

Aunque las aguas son consideradas bienes de propiedad nacional y su distribución debe atender el bienestar general de la población, los usuarios que demandan mayores volúmenes (ciudades, consorcios industriales, mineros, alimenticios, agroindustriales y embotelladores) han desatado una ola de concentración de concesiones arropados por el esquema de opacidad institucional personificado por el Registro Público de Derechos de Agua (REPDA), donde se han documentado prácticas de subregistro, ocultamiento de aprovechamientos y prestanombres. ${ }^{59}$

A través del REPDA las concesiones se han reducido a un conjunto de títulos que pueden ser modificados sin mayor obstáculo por los usuarios poderosos, debido a la flexibilidad y laxitud de las disposiciones contenidas en la LAN. Por el contrario, los derechos de agua de pueblos indígenas y núcleos agrarios frecuentemente se encuentran limitados por el orden jurídico, que restringe muchos de los usos locales con la finalidad de transmitirlos fácilmente a los mercados de agua formales e informales.

57 JACOBO-MARÍN, (2017), pp. 63 y ss.

${ }^{58}$ FARÍAS, U. (1993), Derecho mexicano de aguas nacionales. Legislación, comentarios y jurisprudencia, Porrúa, México, pp. 42-47. Otros juristas clásicos han desarrollado esta hipótesis, véase: GARCÍA, T. (1930), "Registro de concesiones y otros actos en materia minera, petróleo y aguas", Revista General de Derecho y Jurisprudencia, Tomo I, p. 337 y ss. SÁNCHEZ MEJORADA, C. (1944), Notas sobre la evolución y tendencias actuales del derecho minero mexicano, Academia Mexicana de Jurisprudencia y Legislación, México. VÁZQUEZ DEL MERCADO, A. (1946), Concesión minera y derechos reales, Porrúa, México. CASTILLO VELASCO, J. M. (1875), Ensayo sobre el derecho administrativo mexicano, Escuela de Artes y Oficios para Mujeres, México, pp. 12 y ss.

${ }^{59}$ PEÑA, F. (2011), “Acumulación de derechos de agua en México: el poder de las élites”, Justicia hídrica. Acumulación, conflicto y acción social, Pontificia Universidad Católica del Perú-Instituto de Estudios Peruanos-Alianza Internacional Justicia Hídrica, Lima, p. 213.

Revista de Estudios Jurídicos nº 20/2020 (Segunda Época)

ISSN-e 2340-5066. Universidad de Jaén (España)

Versión electrónica: rej.ujaen.es 
Este mecanismo de trasmisión individualizada por concesiones atenta contra la gestión comunitaria del agua y los sistemas hidráulicos tradicionales sustentados en los derechos territoriales. ${ }^{60}$ Sobre todo, si se considera que la demanda de agua para los procesos productivos y extractivos influye directamente en el acceso al líquido para otros usuarios. En tal sentido, los pequeños productores agrícolas han tenido históricamente derechos de agua insuficientemente definidos, en tanto se preservan los de consorcios industriales, alimenticios, embotelladores, mineros y agroindustriales. ${ }^{61}$

La concentración de concesiones no sólo se debe al diseño instrumental para registrar y publicitar los derechos de agua, también involucra el clientelismo político vigente, que facilita el acaparamiento de aprovechamientos y las nuevas apropiaciones de agua. Por esta razón, el agua se acumula en manos de pocos usuarios dominantes, quienes se interesan en transformarla en un beneficio inmediato. ${ }^{62}$

La transferencia de derechos comunitarios de agua para dar lugar a concesiones industriales acentúa la expropiación formal e informal, mediante un proceso de despojo hídrico que desplaza las zonas de cultivo y disocia la relación entre los derechos de agua y la propiedad agrícola campesina. Así lo mostró la reforma agraria de 1992 que, para facilitar la entrada en vigor del TLCAN, modificó las normas protectoras de la propiedad ejidal y comunal. La enmienda gestionó la capitalización del campo, la intervención en la organización de los núcleos agrarios y la flexibilización del régimen de propiedad social colectiva. A manera de ejemplo, se impulsó la adopción del dominio pleno en tierras parceladas con la intención de trasmutar su naturaleza social en unidades productivas y sociedades mercantiles. ${ }^{63}$

Por esta razón, no sorprende que se subestime la aplicación del principio precautorio ambiental para salvaguardar los derechos territoriales de las comunidades potencialmente afectadas, no obstante que el artículo 15 del Convenio 169 de la Organización Internacional del Trabajo (OIT) estipula la especial protección de los recursos naturales existentes en tierras de los pueblos originarios. ${ }^{64}$ De esta manera, las comunidades campesinas y los pueblos indígenas padecen los juegos de poder de las autoridades, las élites locales y las compañías trasnacionales para usurpar los territorios, así como rechazar y destruir los derechos comunitarios de agua y las reglas locales de gestión. ${ }^{65}$

\footnotetext{
${ }^{60}$ HIDALGO, J. P., BOELENS, R. y VOS, J. (2017), “De-colonizing water. Dispossession, water insecurity, and Indigenous claims for resources, authority, and territory”, Water History, vol. 9, n 1, pp. 67-85.

${ }^{61}$ PERREAULT, T. (2013), “¿Despojo por acumulación? Minería, agua y justicia social en el Altiplano boliviano”, Aguas robadas: despojo hídrico y movilización social, Alianza Internacional Justicia HídricaInstituto de Estudios Peruanos-Abya-Yala, Lima, p. 188.

62 BOELENS, R., CREMERS, L. y ZWARTEVEEN, M. (2011), “Justicia hídrica: acumulación de agua, conflictos y acción de la sociedad civil”, Justicia hídrica. Acumulación, conflicto y acción social, Pontificia Universidad Católica del Perú-Instituto de Estudios Peruanos-Alianza Internacional Justicia Hídrica, Lima, pp. 13-25.

63 JACOBO-MARÍN, (2019), pp. 134 y ss.

${ }^{64}$ El Convenio 169 de la OIT sobre Pueblos Indígenas y Tribales en Países Independientes fue ratificado por el Estado mexicano el 13 de agosto de 1990. Hasta el año 2016 sólo ha sido ratificado por 22 países.

${ }^{65}$ BOELENS, R. (2011), "Luchas y defensas escondidas. Pluralismo legal y cultural como una práctica de resistencia creativa en la gestión local del agua en los Andes”, Anuario de Estudios Americanos, vol. 68, n 2, pp. 674-675.
}

Revista de Estudios Jurídicos n 20/2020 (Segunda Época)

ISSN-e 2340-5066. Universidad de Jaén (España)

Versión electrónica: rej.ujaen.es 


\section{CONSIDERACIONES FINALES}

De acuerdo con la hipótesis propuesta en este trabajo, la legislación que derivó de la reforma constitucional energética aprovechó la coyuntura generada en la legislación sobre aguas nacionales para reglamentar la fractura hidráulica y, de ese modo, intervenir el orden de prelación de los usos del agua en México. De esta manera, la LAN fue usada como una plataforma jurídica en vías de abrogación para reglamentar el aprovechamiento preferente del agua para la obtención de recursos fósiles. En este contexto, la reglamentación de la fractura hidráulica no transitó por el proceso legislativo ordinario, lo que evitó el debate parlamentario y las controversias jurisdiccionales que generaría la eventual aprobación de la técnica en ese ámbito. De modo que la legislación reglamentaria también avaló que los operadores del mercado de extracción emplearan el nuevo marco legal para amplificar la exploración y garantizar la obtención de concesiones de derechos de agua.

La profusa demanda de gas propició que las técnicas de exploración evolucionaran a la par de la acumulación masiva de yacimientos no convencionales, de manera que la industria extractiva diversificó sus inversiones y desarrolló insumos tecnológicos que le permitieron mayor rentabilidad. La combinación de técnicas de perforación y la posibilidad de obtener recursos fósiles mediante la estimulación artificial apuntalaron la ola extractiva. Con base en los principios de prevención y de precaución, el fracking ha sido prohibido en Francia, Bulgaria y los estados de Vermont, Nueva York y Maryland (EUA), además se aprobaron moratorias para su realización en Reino Unido. Sin embargo, su uso se impulsa bajo el discurso que la considera una práctica económicamente rentable en aras de alcanzar la seguridad energética.

Con el objetivo de garantizar la provisión de energéticos para la población, la reforma posibilitó la transacción de los bienes naturales empleados en la generación de energía fósil. En ese sentido, los informes públicos subrayaron que la modificación constitucional se impulsó como una maniobra jurídica necesaria para asegurar el abasto asequible, continuo y confiable de combustibles. Bajo este escenario, los derechos comunitarios de agua se ven amenazados frente a los lineamientos que regulan el fracking, no sólo porque los aprovechamientos comunitarios se asumen como insumos energéticos, también porque el uso de la técnica reproduce el esquema de contaminación del agua.

La reglamentación de la fractura hidráulica en México mediante lineamientos administrativos permitió, de forma concomitante, la apertura de las solicitudes para el otorgamiento de permisos en el sector de la estimulación artificial de yacimientos no convencionales. De este modo, se concluye que se trata de la configuración de mecanismos legales que fortalecen el modelo de dependencia de los combustibles fósiles y promueven los proyectos extractivos de capital privado trasnacional en las actividades de refinación, transporte, almacenamiento, distribución y comercialización, antes consideradas actividades exclusivas del Estado mexicano. Las modificaciones impulsadas sólo acentuarán los riesgos de proximidad con los proyectos energéticos, el desplazamiento forzoso de las poblaciones cercanas y el deterioro de las condiciones biofísicas, en tanto las corporaciones hacen negocios redituables. 


\section{BIBLIOGRAFÍA}

ANGLÉS HERNÁNDEZ, M. (2017), “La reforma en materia de hidrocarburos en México, como parte del proyecto neoliberal hegemónico violatorio de derechos humanos", Reforma en materia de hidrocarburos. Análisis jurídicos, sociales y ambientales en prospectiva, IIJ-UNAM-Universidad Autónoma de Tamaulipas, México.

BASSOLS BATALLA, N. (2006), Las etapas de la nacionalización petrolera, Porrúa, México.

BOELENS, R. (2011), "Luchas y defensas escondidas. Pluralismo legal y cultural como una práctica de resistencia creativa en la gestión local del agua en los Andes”, Anuario de Estudios Americanos, vol. 68, n ${ }^{\circ} 2$.

BOELENS, R., CREMERS, L. y ZWARTEVEEN, M. (2011), "Justicia hídrica: acumulación de agua, conflictos y acción de la sociedad civil”, Justicia hídrica. Acumulación, conflicto y acción social, Pontificia Universidad Católica del PerúInstituto de Estudios Peruanos-Alianza Internacional Justicia Hídrica, Lima.

BUDDS, J. (2011), “Relaciones sociales de poder y la producción de paisajes hídricos”, Justicia hídrica. Acumulación, conflicto y acción social, Pontificia Universidad Católica del Perú-Instituto de Estudios Peruanos-Alianza Internacional Justicia Hídrica, Lima.

CANTONI, R., et al. (2018), "Shale Tales: Politics of Knowledge and Promises in Europe's Shale Gas Discourses”, The Extractive Industries and Society, vol. 5, n 4.

CARBONELL LEÓN, M. N. (2017), “Fracturación hidráulica y principio precautorio”, Reforma en materia de hidrocarburos. Análisis jurídicos, sociales y ambientales en prospectiva, IIJ-UNAM-Universidad Autónoma de Tamaulipas, México.

CÁRDENAS GRACIA, J. (2014), Crítica a la reforma constitucional energética de 2013, IIJ-UNAM, México.

CASTILLO VELASCO, J. M. (1875), Ensayo sobre el derecho administrativo mexicano, Escuela de Artes y Oficios para Mujeres, México.

COMISIÓN NACIONAL DE HIDROCARBUROS (2019), “El fracturamiento hidráulico es una técnica de producción de uso intensivo en campos de gas”, informe, 20 de agosto, México. [Disponible en: https://hidrocarburos.gob.mx/media/2792/pozoscon-fracturamiento_200819.pdf]

FARÍAS, U. (1993), Derecho mexicano de aguas nacionales. Legislación, comentarios y jurisprudencia, Porrúa, México.

FLEMING, R. (2017), “The New German Fracking Package”, Journal of Energy \& Natural Resources Law, vol. 35, $\mathrm{n}^{0} 3$.

GAGNON, G. A., et al. (2016), "Impacts of hydraulic fracturing on water quality: a review of literature, regulatory frameworks and an analysis of information gaps”, Environmental Reviews, vol. 24, $\mathrm{n}^{\circ} 2$.

GARCÍA, T. (1930), "Registro de concesiones y otros actos en materia minera, petróleo y aguas”, Revista General de Derecho y Jurisprudencia, Tomo I.

GOLDEN, J. y WISEMAN, H. (2015), “The Fracking Revolution: Shale Gas as a Case Study in Innovation Policy”, Emory Law Journal, vol. 64, n 4.

Revista de Estudios Jurídicos nº 20/2020 (Segunda Época)

ISSN-e 2340-5066. Universidad de Jaén (España)

Versión electrónica: rej.ujaen.es 
HATCH KURI, G. (2018), "Fracking en el Acuífero Transfronterizo Edwards-Trinity-El Burro: implicaciones y daños ambientales transfronterizos”, Investigaciones Geográficas, n ${ }^{\circ} 96$.

HIDALGO, J. P., BOELENS, R. y VOS, J. (2017), "De-colonizing water. Dispossession, water insecurity, and Indigenous claims for resources, authority, and territory", Water History, vol. 9, n ${ }^{\circ} 1$.

ISCH, E. (2015), “Geopolítica regional de la hidroenergía: ¿A dónde irá la energía de Ecuador y del resto de los países?”, (In) Justicia Hídrica. Resistencias y Alternativas en América Latina, $\mathrm{n}^{\circ}$ 2, CBC-Alianza Internacional Justicia Hídrica, Medellín.

ISCH, E. (2011), “La contaminación del agua como proceso de acumulación”, Justicia hídrica. Acumulación, conflicto y acción social, Pontificia Universidad Católica del Perú-Instituto de Estudios Peruanos-Alianza Internacional Justicia Hídrica, Lima.

JACOBO-MARÍN, D. (2019), "Apología de la extracción, acumulación de derechos de agua y despojo por contaminación. Legados de la reforma energética en México”, Revista de Derechos Humanos y Estudios Sociales, año XI, $n^{\circ} 22$.

JACOBO-MARÍN, D. (2017), "Si el agua es poca, a la ciudad le toca. Demanda urbana y derechos de agua en la ciudad de San Luis Potosí, México", (In) Justicia Hídrica. Resistencias y Alternativas en América Latina, $\mathrm{n}^{\circ}$ 3, CBC-Alianza Internacional Justicia Hídrica, Medellín.

JACOBO-MARÍN, D. (2016), Análisis de concordancia entre la Ley de Hidrocarburos y la Ley Minera con la Iniciativa Ciudadana de Ley General de Aguas, Coordinadora Nacional Agua para Todos, Agua para la Vida, México.

LANZ CÁRDENAS, J. T. (1982), Legislación de aguas en México. Estudio históricolegislativo de 1521-1981, 4 vols., Gobierno del Estado de Tabasco, Villahermosa.

LEES, Z. (2012), “Anticipated Harm, Precautionary Regulation and Hydraulic Fracturing”, Vermont Journal of Environmental Law, vol. 13.

LEIFSEN, E. (2017), "Wasteland by design: Dispossession by contamination and the struggle for water justice in the Ecuadorian Amazon", The Extractive Industries and Society, vol. 4, ${ }^{\circ} 2$.

PEÑA, F. (2011), “Acumulación de derechos de agua en México: el poder de las élites”, Justicia hídrica. Acumulación, conflicto y acción social, Pontificia Universidad Católica del Perú-Instituto de Estudios Peruanos-Alianza Internacional Justicia Hídrica, Lima.

PERREAULT, T. (2013), “¿Despojo por acumulación? Minería, agua y justicia social en el Altiplano boliviano”, Aguas robadas: despojo hídrico y movilización social, Alianza Internacional Justicia Hídrica-Instituto de Estudios Peruanos-Abya-Yala, Lima.

SÁNCHEZ MEJORADA, C. (1944), Notas sobre la evolución y tendencias actuales del derecho minero mexicano, Academia Mexicana de Jurisprudencia y Legislación, México.

SECRETARÍA DE ENERGÍA (2017), Plan quinquenal de licitaciones para la exploración y extracción de hidrocarburos 2015-2019, Secretaría de Energía-Subsecretaría de Hidrocarburos, México.

Revista de Estudios Jurídicos no 20/2020 (Segunda Época)

ISSN-e 2340-5066. Universidad de Jaén (España)

Versión electrónica: rej.ujaen.es 
SENADO DE LA REPÚBLICA (2014), Presentación de las iniciativas de las Leyes Secundarias de la Reforma Constitucional en Materia de Energía enviadas al Senado de la República por el Poder Ejecutivo Federal, Comisión de Energía del Senado de la República, México.

VALDÉS AGUIRRE, C. L. (2018), Aplicación del principio precautorio a la fractura hidráulica: análisis multidisciplinario del marco regulador en los Estados Unidos, México y la Unión Europea, Tesis Doctoral, Universidad Complutense, Madrid.

VARGAS, R. (2015), “La reforma energética: a 20 años del TLCAN”, Problemas del Desarrollo, vol. 46, n 180.

VARGAS, R. y BARRIOS, H. (2013), “El impacto geopolítico de la revolución del gas de esquisto: consideraciones para México”, El Cotidiano, nº 177.

VÁZQUEZ DEL MERCADO, A. (1946), Concesión minera y derechos reales, Porrúa, México.

VERA VÁZQUEZ, R. (2015), “Actividad petrolera en el Golfo de México: historia, derrames y política internacional de integridad de los océanos”, Los hidrocarburos en el noreste de México, Universidad Autónoma de Tamaulipas-El Colegio de Tamaulipas, Ciudad Victoria.

WOOD, A. (2016), A Look at the Future of the Mexican Petroleum Industry after Energy Reform, Wilson Center-Mexico Institute, Washington.

\section{LEGISLACIÓN}

BOLETÍN OFICIAL DEL ESTADO (1986), Real Decreto 849/1986, de 11 de abril, por el que se aprueba el Reglamento del Dominio Público Hidráulico, que desarrolla los títulos preliminares, I, IV, V, VI y VII de la Ley 29/1985, de 2 de agosto, de Aguas. Madrid, Ministerio de Obras Públicas y Urbanismo, BOE-A-1986-10638, núm. 103, 30 de abril.

DIARIO OFICIAL DE LA FEDERACIÓN (2017), Lineamientos para la protección y conservación de las aguas nacionales en actividades de exploración y extracción de hidrocarburos en yacimientos no convencionales, México, 30 de agosto.

DIARIO OFICIAL DE LA FEDERACIÓN (2017), Disposiciones administrativas de carácter general que establecen los lineamientos en materia de seguridad industrial, seguridad operativa y protección al medio ambiente para realizar las actividades de exploración y extracción de hidrocarburos en yacimientos no convencionales en tierra, México, 16 de marzo.

DIARIO OFICIAL DE LA FEDERACIÓN (2016), Decreto por el que se reforman y adicionan diversas disposiciones de la Ley de Aguas Nacionales, México, 24 de marzo.

DIARIO OFICIAL DE LA FEDERACIÓN (2013), Decreto por el que se reforman y adicionan diversas disposiciones de la Constitución Política de los Estados Unidos Mexicanos, en Materia de Energía, México, 20 de diciembre.

DIARIO OFICIAL DE LA FEDERACIÓN (2012), Decreto por el que se declara reformado el párrafo quinto y se adiciona un párrafo sexto, recorriéndose en su

Revista de Estudios Jurídicos nº 20/2020 (Segunda Época)

ISSN-e 2340-5066. Universidad de Jaén (España)

Versión electrónica: rej.ujaen.es 
orden los subsecuentes, al artículo 40 de la Constitución Política de los Estados Unidos Mexicanos, México, 8 de febrero.

DIARIO OFICIAL DE LA FEDERACIÓN (1989), Decreto por el que crea la Comisión Nacional del Agua como órgano administrativo desconcentrado de la Secretaría de Agricultura y Recursos Hidráulicos, México, 16 de enero.

DIARIO OFICIAL DE LA UNIÓN EUROPEA (2012), Versión consolidada del Tratado de la Unión Europea, (C 326/13).

DIARIO OFICIAL DE LA UNIÓN EUROPEA (2011), Directiva 2011/92/UE del Parlamento Europeo y del Consejo, de 13 de diciembre de 2011, relativa a la evaluación de las repercusiones de determinados proyectos públicos y privados sobre el medio ambiente, (L 26/1).

DIARIO OFICIAL DE LA UNIÓN EUROPEA (2010), Versión consolidada del Tratado de Funcionamiento de la Unión Europea, (C 83/47).

DIARIO OFICIAL DE LA UNIÓN EUROPEA (2006), Directiva 2006/21/CE del Parlamento Europeo y del Consejo, de 15 de marzo de 2006, sobre la gestión de los residuos de industrias extractivas y por la que se modifica la Directiva 2004/35/CE, (L 102/15).

DIARIO OFICIAL DE LA UNIÓN EUROPEA (2000), Directiva 2000/60/CE del Parlamento Europeo y del Consejo, de 23 de octubre de 2000, por la que se establece un marco comunitario de actuación en el ámbito de la política de aguas, (L 327/1).

\section{SIGLAS UTILIZADAS}

AIE: Agencia Internacional de Energía.

ASEA: Agencia Nacional de Seguridad Industrial y de Protección al Medio Ambiente del Sector Hidrocarburos.

CONAGUA: Comisión Nacional del Agua.

CFE: Comisión Federal de Electricidad.

CNH: Comisión Nacional de Hidrocarburos.

CPEUM: Constitución Política de los Estados Unidos Mexicanos.

CRE: Comisión Reguladora de Energía.

DOF: Diario Oficial de la Federación.

EUA: Estados Unidos de América.

LAN: Ley de Aguas Nacionales.

LGA: Ley General de Aguas.

MIA: Manifestación de Impacto Ambiental.

OIT: Organización Internacional del Trabajo.

PEMEX: Petróleos Mexicanos.

REPDA: Registro Público de Derechos de Agua.

SENER: Secretaría de Energía.

TFUE: Tratado de Funcionamiento de la Unión Europea.

TLCAN: Tratado de Libre Comercio de América del Norte. También se conoce como NAFTA (North American Free Trade Agreement). 
TUE: Tratado de la Unión Europea.

UE: Unión Europea.

\section{TABLAS (ANEXOS)}

TABLA 1. INICIATIVAS ENVIADAS POR EL PODER EJECUTIVO FEDERAL AL CONGRESO DE LA UNIÓN EN EL MARCO DE LA REFORMA CONSTITUCIONAL ENERGÉTICA DE 2013

\begin{tabular}{|c|c|c|c|}
\hline Iniciativa & $\begin{array}{l}\text { Artículos constitucionales } \\
\text { (ordinarios y transitorios) }\end{array}$ & $\begin{array}{l}\text { Efecto jurídico } \\
\text { material }\end{array}$ & $\begin{array}{c}\text { Entidad } \\
\text { dictaminadora* }\end{array}$ \\
\hline Hidrocarburos & $\begin{array}{c}27 \text { y } 28 \\
\text { Transitorios 4, 5, 7, } 8 \text { y } 16\end{array}$ & \multirow{5}{*}{$\begin{array}{l}\text { Creación de } \\
\text { nueve leyes }\end{array}$} & \multirow{6}{*}{$\begin{array}{l}\text { Senado de la } \\
\text { República }\end{array}$} \\
\hline Energía eléctrica & $\begin{array}{c}27 \text { y } 28 \\
\text { Transitorios } 4 \text { y } 11\end{array}$ & & \\
\hline Geotermia & $\begin{array}{c}25 \\
\text { Transitorios } 11,17 \text { y } 18\end{array}$ & & \\
\hline $\begin{array}{l}\text { Agencia Nacional de } \\
\text { Seguridad }\end{array}$ & $\begin{array}{c}25 \\
\text { Transitorios } 17 \text { y } 19\end{array}$ & & \\
\hline $\begin{array}{c}\text { Empresas productivas } \\
\text { del Estado }\end{array}$ & $\begin{array}{c}28 \\
\text { Transitorios } 3 \text { y } 20\end{array}$ & & \\
\hline $\begin{array}{l}\text { Reguladores en la } \\
\text { Ley Orgánica de la } \\
\text { Administración } \\
\text { Pública Federal }\end{array}$ & $\begin{array}{c}28 \\
\text { Transitorios } 10,12 \text { y } 13\end{array}$ & \multirow{4}{*}{$\begin{array}{l}\text { Modificación } \\
\text { de doce leyes }\end{array}$} & \\
\hline Decreto fiscal & $\begin{array}{l}27 \\
\text { Transitorios 4, 5, 9, } 11 \text { y } 14\end{array}$ & & \multirow{3}{*}{$\begin{array}{l}\text { Cámara de } \\
\text { Diputados }\end{array}$} \\
\hline $\begin{array}{l}\text { Fondo Mexicano del } \\
\text { Petróleo }\end{array}$ & $\begin{array}{c}28 \\
\text { Transitorios } 14 \text { y } 15\end{array}$ & & \\
\hline $\begin{array}{c}\text { Decreto } \\
\text { presupuestario }\end{array}$ & $\begin{array}{c}27 \\
\text { Transitorios } 14 \text { y } 21\end{array}$ & & \\
\hline \multicolumn{4}{|c|}{$\begin{array}{l}\text { * En México el Poder Legislativo se deposita en un Congreso general que se divide en } \\
\text { dos cámaras, una de diputados y otra de senadores, de acuerdo con el artículo } 50 \\
\text { constitucional. }\end{array}$} \\
\hline
\end{tabular}

Fuente: Elaboración del autor con base en Senado de la República (2014). 


\section{TABLA 2. MARCO LEGAL ENERGÉTICO EN MÉXICO A PARTIR DE LA REFORMA CONSTITUCIONAL DE 20 DE DICIEMBRE DE 2013, REGLAMENTADA EL 11 DE AGOSTO DE 2014}

\begin{tabular}{|c|c|c|c|}
\hline Ordenamiento & $\begin{array}{l}\text { Materia u órgano } \\
\text { que regula }\end{array}$ & Naturaleza normativa & Concordancia* \\
\hline $\begin{array}{c}\text { Ley de } \\
\text { Hidrocarburos }\end{array}$ & Hidrocarburos & $\begin{array}{l}\text { Ley reglamentaria de los } \\
\text { artículos 25, párrafo cuarto; 27, } \\
\text { párrafo séptimo y } \\
\text { 28, párrafo cuarto de la } \\
\text { Constitución Política de los } \\
\text { Estados Unidos Mexicanos } \\
\text { (CPEUM) }\end{array}$ & \multirow[t]{2}{*}{$\begin{array}{c}\text { Ley de Inversión } \\
\text { Extranjera } \\
\\
\text { Ley de } \\
\text { Asociaciones } \\
\text { Público Privadas }\end{array}$} \\
\hline Ley Minera & Minerales & $\begin{array}{c}\text { Ley reglamentaria del artículo } \\
27 \text { de la CPEUM en matera } \\
\text { minera }\end{array}$ & \\
\hline $\begin{array}{l}\text { Ley de } \\
\text { Petróleos } \\
\text { Mexicanos }\end{array}$ & $\begin{array}{l}\text { Empresa } \\
\text { paraestatal } \\
\text { Petróleos } \\
\text { Mexicanos } \\
\text { (Pemex) }\end{array}$ & $\begin{array}{l}\text { Ley reglamentaria del párrafo } \\
\text { cuarto del artículo } 25 \text { de la } \\
\text { CPEUM y del artículo } \\
\text { transitorio vigésimo del } \\
\text { Decreto de } 20 \text { de diciembre de } \\
2013\end{array}$ & \multirow{2}{*}{\begin{tabular}{|c} 
Ley Federal de las \\
Entidades \\
Paraestatales \\
\\
Ley de \\
Adquisiciones, \\
Arrendamientos y \\
Servicios del \\
Sector Público \\
\\
Ley de Obras \\
Públicas y \\
Servicios \\
Relacionados con \\
las Mismas
\end{tabular}} \\
\hline $\begin{array}{l}\text { Ley de la } \\
\text { Comisión } \\
\text { Federal de } \\
\text { Electricidad }\end{array}$ & $\begin{array}{l}\text { Empresa } \\
\text { productiva del } \\
\text { Estado Comisión } \\
\text { Federal de } \\
\text { Electricidad } \\
\text { (CFE) }\end{array}$ & $\begin{array}{l}\text { Ley reglamentaria del párrafo } \\
\text { cuarto del artículo } 25 \text { de la } \\
\text { CPEUM y del artículo } \\
\text { transitorio vigésimo del } \\
\text { Decreto de } 20 \text { de diciembre de } \\
2013\end{array}$ & \\
\hline $\begin{array}{l}\text { Ley de la } \\
\text { Industria } \\
\text { Eléctrica }\end{array}$ & $\begin{array}{c}\text { Industria } \\
\text { eléctrica, } \\
\text { incluidos el } \\
\text { Sistema Eléctrico } \\
\text { Nacional y el } \\
\text { Servicio Público } \\
\text { de Transmisión y } \\
\text { Distribución de } \\
\text { Energía Eléctrica }\end{array}$ & $\begin{array}{l}\text { Ley reglamentaria de los } \\
\text { artículos 25, párrafo cuarto; } 27, \\
\text { párrafo sexto y } 28 \text { de la } \\
\text { CPEUM }\end{array}$ & $\begin{array}{l}\text { Ley de Aguas } \\
\text { Nacionales }\end{array}$ \\
\hline
\end{tabular}




\begin{tabular}{|c|c|c|c|}
\hline $\begin{array}{l}\text { Ley de } \\
\text { Energía } \\
\text { Geotérmica }\end{array}$ & $\begin{array}{l}\text { Recursos } \\
\text { geotérmicos y } \\
\text { energía térmica } \\
\text { del subsuelo }\end{array}$ & $\begin{array}{c}\text { Ley reglamentaria } \\
\text { (regula el reconocimiento, la } \\
\text { exploración y la explotación de } \\
\text { recursos geotérmicos, con el } \\
\text { fin de generar energía eléctrica } \\
\text { y destinarla a diversos usos) }\end{array}$ & \\
\hline $\begin{array}{l}\text { Ley de los } \\
\text { Órganos } \\
\text { Reguladores } \\
\text { Coordinados } \\
\text { en Materia } \\
\text { Energética }\end{array}$ & $\begin{array}{l}\text { Comisión } \\
\text { Nacional de } \\
\text { Hidrocarburos y } \\
\text { Comisión } \\
\text { Reguladora de } \\
\text { Energía }\end{array}$ & $\begin{array}{c}\text { Ley reglamentaria del párrafo } \\
\text { octavo del artículo } 28 \text { de la } \\
\text { CPEUM }\end{array}$ & \multirow[b]{2}{*}{$\begin{array}{l}\text { Ley Orgánica de } \\
\text { la Administración } \\
\text { Pública Federal }\end{array}$} \\
\hline $\begin{array}{l}\text { Ley de la } \\
\text { Agencia } \\
\text { Nacional de } \\
\text { Seguridad } \\
\text { Industrial y de } \\
\text { Protección al } \\
\text { Medio } \\
\text { Ambiente del } \\
\text { Sector } \\
\text { Hidrocarburos }\end{array}$ & $\begin{array}{l}\text { Agencia Nacional } \\
\text { de Seguridad } \\
\text { Industrial y de } \\
\text { Protección al } \\
\text { Medio Ambiente } \\
\text { del Sector } \\
\text { Hidrocarburos } \\
\text { (ASEA) }\end{array}$ & $\begin{array}{c}\text { Ley orgánica } \\
\text { (protección de las personas, el } \\
\text { medio ambiente y las } \\
\text { instalaciones del sector de } \\
\text { hidrocarburos a través de la } \\
\text { ASEA) }\end{array}$ & \\
\hline $\begin{array}{l}\text { Ley de } \\
\text { Ingresos } \\
\text { sobre } \\
\text { Hidrocarburos }\end{array}$ & $\begin{array}{c}\text { Ingresos del } \\
\text { Estado mexicano } \\
\text { por las } \\
\text { actividades de } \\
\text { exploración y } \\
\text { extracción de } \\
\text { hidrocarburos }\end{array}$ & $\begin{array}{l}\text { Ley ordinaria } \\
\text { (establece el régimen de } \\
\text { ingresos que recibe el Estado } \\
\text { mexicano derivados de las } \\
\text { actividades de exploración y } \\
\text { extracción de hidrocarburos } \\
\text { que se realizan a través de } \\
\text { asignaciones y contratos, } \\
\text { regulados en el séptimo párrafo } \\
\text { del artículo } 27 \text { de la CPEUM) }\end{array}$ & \multirow{2}{*}{$\begin{array}{c}\text { Ley Federal de } \\
\text { Derechos } \\
\text { Ley de } \\
\text { Coordinación } \\
\text { Fiscal } \\
\text { Ley Federal de } \\
\text { Presupuesto y } \\
\text { Responsabilidad } \\
\text { Hacendaria } \\
\text { Ley General de } \\
\text { Deuda Pública }\end{array}$} \\
\hline $\begin{array}{c}\text { Ley del } \\
\text { Fondo } \\
\text { Mexicano del } \\
\text { Petróleo para } \\
\text { la } \\
\text { Estabilización } \\
\text { y el } \\
\text { Desarrollo } \\
\end{array}$ & $\begin{array}{l}\text { Fondo Mexicano } \\
\text { del Petróleo para } \\
\text { la Estabilización } \\
\text { y el Desarrollo }\end{array}$ & $\begin{array}{c}\text { Ley orgánica } \\
\text { (ingresos derivados de las } \\
\text { asignaciones y los contratos } \\
\text { regulados en el párrafo séptimo } \\
\text { del artículo } 27 \text { de la CPEUM) }\end{array}$ & \\
\hline
\end{tabular}


Fractura hidráulica en México: una mirada desde la reforma constitucional energética y los derechos comunitarios de agua

* Se refiere a la vinculación normativa que debe guardar la ley citada con otras normas vigentes en México.

Fuente: Elaboración del autor con base en el Diario Oficial de la Federación (2013) y Senado de la República (2014). 